\title{
A Classroom of Bunnies, Blimps, and Werewolves: Teaching Asian Religions Online in Second Life
}

\begin{abstract}
M. Alyson Prude
Abstract: Virtual environments promise a myriad of exciting opportunities for college and university online teaching, but how much do they actually deliver? This evaluation of the use of Second Life in an Asian religions course contributes to the small but growing body of literature addressing the incorporation of online virtual worlds into higher education. It discusses benefits and drawbacks of teaching in Second Life and suggests Asian-inspired Second Life locations that can be useful in the classroom. Given instructor commitment to making use of the unique possibilities Second Life offers, including synchronous communication, virtual world fieldtrips, animations, and the potential for guest lectures and international participation, Second Life can provide a lively and interesting alternative for online Asiancontent courses.
\end{abstract}

Keywords Second Life; Online education; Instructional Technology

Online education is frequently criticized for being impersonal, anonymous, and characterized by monologue as opposed to dialogue. "The Internet teacher," Edmundson (2012) writes, "even one who responds to students via e-mail, can never have the immediacy of contact that the teacher on the scene can, with his sensitivity to unspoken moods and enthusiasms." To address this shortcoming, increasing numbers of higher-education faculty are experimenting with synchronous options for online learning. Among the choices are 3D virtual environments which, their proponents argue, provide an increased sense of social presence, "a feeling of actually "being there"' (Van der Land et al. 2011: 1). Opportunities for real-time interaction between students and faculty, it is argued, lead to a higher quantity and quality of two-way communication and a greater depth of student learning. Theoretically, virtual worlds promise a myriad of exciting opportunities, but how much do they actually deliver? Because the use of virtual worlds in education is relatively new, scholars continue to call for concrete reports of student and faculty experiences using them in the classroom. ${ }^{1}$ This paper is an evaluation of the use of the virtual world Second Life (henceforth SL) to teach a course in Asian religions. As such, it contributes to the small but growing body of literature addressing the use of online virtual worlds in college and university teaching. ${ }^{2}$ It discusses benefits and drawbacks of teaching in a virtual environment and suggests Asian-inspired locations within SL that can be useful in the classroom. Based on my experience using SL to teach about Asian religions, I argue that with instructor commitment to making use of the unique opportunities SL provides, as well as institutional IT support, SL can provide a lively and interesting alternative for online Asian-content courses.

\section{COURSE DESCRIPTION AND RATIONALE FOR USING SECOND LIFE}

During the spring semester of 2012, I taught an online upper-division Religious Studies course at the University of Wisconsin-Whitewater (UWW) titled "Eastern Religious Thought.” The course surveyed the Hindu, Buddhist, Confucian, Daoist, Shinto, and Sikh
M. Alyson Prude received her $\mathrm{PhD}$ in Religious Studies from the University of California, Santa Barbara. She came to the University of Wisconsin-Whitewater for the year 2011-2012 as an ASIANetwork-Luce Foundation Postdoctoral Teaching Fellow. This article is based on the online course she taught as a postdoctoral fellow in the Department of Philosophy and Religious Studies. 
traditions as well as Tantra and indigenous shamanic and oracular practices. For the nuts and bolts of the class, we used the web-based course management system, Desire2Learn (D2L), where I uploaded syllabus documents, reading and homework assignments, and links to videos and Internet sites.

Teaching online is an ideal venue for tapping into the vast array of multi-media content available on the Internet. During our unit on India, we watched a YouTube clip from the Indian TV serial Ramāyana and used it to discuss the Hindu concept of dharma. In our week on Sikhism, we viewed clips of a Sikh kirtan, or devotional service, and a short PBS Religion \& Ethics NewsWeekly documentary about a Hindu-Sikh marriage. We used Buddhism to take us from South Asia to East Asia, where we examined a video of a meeting between Zen monks and their master in which the monks attempt to demonstrate their understanding of a kōan. During the remainder of the semester, we surveyed Confucianism, Daoism, and Shintō, as well as Tantra and the indigenous practices of oracle-possession, and Nepali, Mongolian, and Korean shamanism. Video content in particular stimulated lively conversations on our D2L discussion board.

Calvert-Minor argues that students in philosophy courses "need synchronous dialogue. Students need the presence of others to listen to their philosophical thoughts and arguments, and then have those others give immediate feedback" (Calvert-Minor 2011: 4). Similarly, in his critique of online teaching, Edmundson (2012) describes teaching as "a matter of dialogue" and a "truly memorable" class as a "one-time-only event." Real-time lecture meetings are especially helpful for students who are audio learners and for those who have trouble comprehending the assigned reading on their own. In order to provide a real-time, live element to students' online experience, I considered both SL and WebEx as platforms for delivering weekly synchronous lecture presentations.

After consultation with department colleagues, and despite the reservations of UWW's College of Letters and Science's academic IT manager, I decided to experiment with SL. SL is a free virtual world of nearly 30 million international users or "residents" who interact via video-game-like personas called avatars. ${ }^{3}$ Avatars communicate with each other via voice chat, text chat, or private instant messaging. When logged on to SL, one's avatar can move through the virtual world by walking, running, flying, or teleporting to distant locations. An influential factor in my decision to use SL and not WebEx was the enthusiasm of a philosophy instructor who had taught in SL successfully over the summer, and who had recently convinced the college to support online instruction in SL. ${ }^{4}$ In addition, I was attracted to SL's visual depth and texture, and curious to try something new. ${ }^{5}$

Thirty-two students pre-registered for the course, approximately two-thirds of whom were exclusively online students while one-third were traditional students who took the course due to interest in the subject matter and despite the fact that it was offered online and not in a traditional classroom. Over the course of the semester, the students and I met fourteen times for 75 minutes a session. During these meetings, I spoke into a headset so that students heard my voice, and I clicked through Power Point slides uploaded into SL. Although SL allows everyone in a given location to speak simultaneously, students did not make use of this option. I continued to encourage them to do so, but they preferred to type their questions and comments into our live chat box, a trend also noted by Calvert-Minor and Herold. Herold (2012) attributes his students' use of text chat to the lack of microphones and speakers on campus computers, but at least half of my students had the capability of engaging in voice chat. They simply chose not to utilize it.

During class, I usually noticed questions as they appeared in the chat box and could give an immediate response. Sometimes, however, referring to my lecture notes while control- 
ling my avatar's movement in order to change PowerPoint slides, and then reorienting my avatar's face towards the class required my full attention. As a result, I periodically paused my lecture to read through student comments and questions in the chat box. Nevertheless, there were frequently questions in the chat $\log$ I noticed only after class had ended. More practice would resolve this issue, but it is something for first-time users to consider. One SL instructor commented that "being a teacher [in SL] was like playing a complicated piece on a church organ, whilst baking a cake and working out a chess problem in your head"' (Petrakou 2010: 1022). I, too, found teaching in SL to require an extraordinary degree of mental multi-tasking.

Students, on the other hand, seemed to have no trouble listening, reading, and typing simultaneously. Unlike in a traditional classroom where students take turns speaking and are often hesitant to answer each other's questions, in SL everyone can "talk" at the same time. Students appreciated the immediacy of SL chats. "In the context of Second Life... the chat room style discussion has a faster pace and you don't have time to prepare your statements at length, so once the ice is broken the discussion can flow more freely and quickly," our student tech assistant commented when I asked for her opinion of SL. On D2L, in contrast, "discussions take place as forum posts which create slow, short discussions... The discussion doesn't flow and the postings feel more like small, prepared pieces of writing meant mostly for the professor to see." The synchronicity of the SL classroom, while a challenge for me as instructor, provided a feeling of "flow" and speed that the tech assistant and students appreciated.

Students' text comments and questions during one 75 minute class typically generated between thirteen and seventeen pages of text chat (when copied and pasted into a Microsoft Word document, 11 point font, single spaced with double spacing between authors). A large portion of the chat content, however, consisted of acknowledgements such as "Yeah," "lol," and "I agree." When I asked yes/no or other questions requiring very short answers, students responded with an immediate stream of replies which I found useful for judging how many of them agreed/disagreed with a statement or understood/didn't understand the point we had just covered. The chat box was less useful for in-depth sustained discussion which occurred later on D2L. As one student noted, "In class [the instructor] will ask questions and start up discussions. It continues on into the discussion boards." 6 The chief advantage of SL's chat box is that it mitigates the lack of community often experienced by online learners

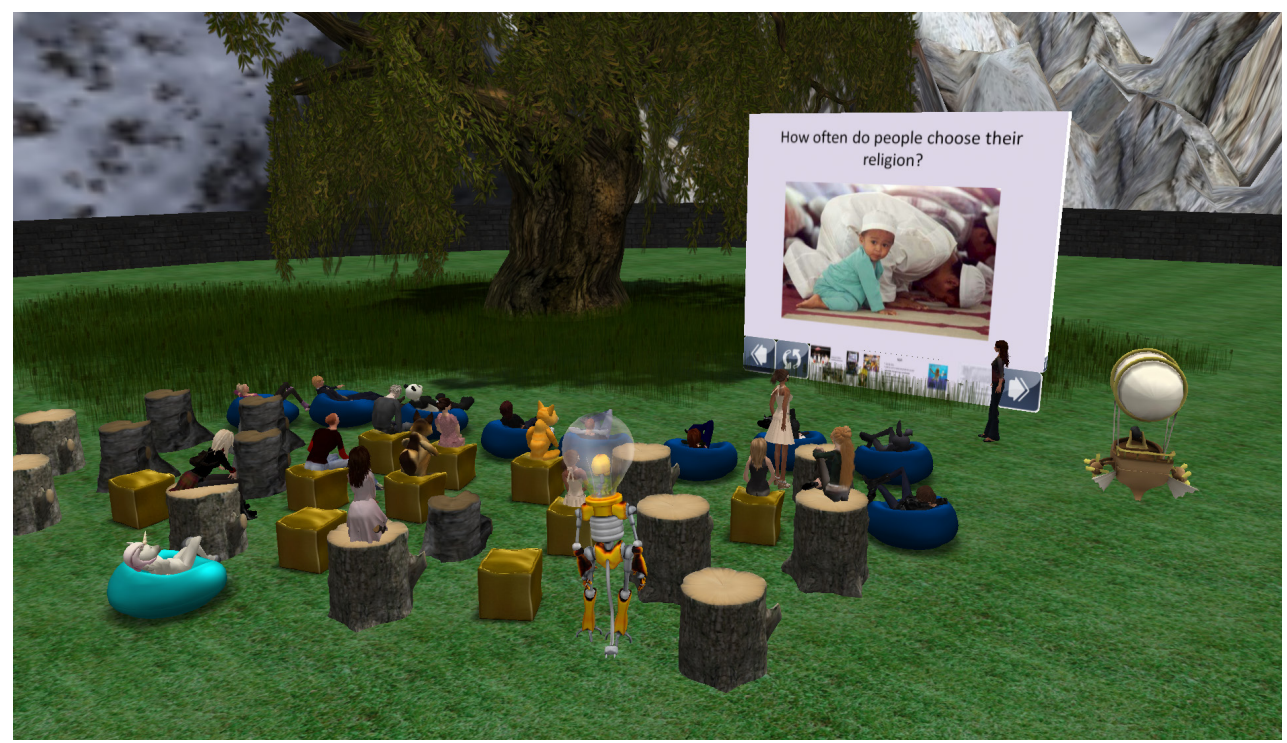

Figure 1: Our virtual classroom for Eastern Religious Thought 
by allowing students to interact with each other in real time. Students who logged on before class began would converse with each other about sports scores, the weather, and current events, as well as difficult homework assignments.

\section{AVATARS AND ANONYMITY}

At the beginning of the semester, when students created SL accounts, they chose or created an avatar, the form in which they appeared to the class. On the advice of my more experienced colleague, I made my avatar as realistic as possible (minus some unwelcome wrinkles and graying hair). Students, however, were free to choose any kind of avatar they liked, as long as it was not inappropriate or overly distracting to the class. ${ }^{7}$ Among our avatars were two dogs, a rabbit, a fox, a panda, a pink unicorn, a robot, a werewolf that let out a startling roar each time the student logged in or out, and a blimp that zoomed around the seating area after each class, performing its own ritual circumambulations.

Students' choice of avatar was unrelated to the content of the course, but the variety of avatar forms impacted the group dynamic in interesting ways. I did not require students to give their avatars names that corresponded with the students' real world identities. If they wished, students could keep their "real" identities secret. While I knew, for example, that one non-human avatar was a grandmother and native Spanish-speaker, because she chose not to share this information with the other students they had no idea that she was not a U.S.-born twenty-something typical undergrad. The results of this anonymity were particularly positive for one shy student. Although he never spoke in class the previous semester, he participated freely and wittily in our SL meetings. ${ }^{8}$ Using the name of a Japanese pop star, he shouted, "IT'S DISCO TIME, BABY!" instead of typing "here" as other students did when they logged in for our online class. ${ }^{9}$

Other studies also report that interacting via avatars reduces user inhibitions and increases sharing and involvement with others. ${ }^{10}$ The "leveling of identity" that occurs within online environments due to the ability to disguise one's voice, body shape, gender, age, etc. has been discussed by numerous researchers including Steinkuehler and Williams, who argue that platforms such as SL are "particularly well suited to... bridging social capital" (Steinkuehler and Williams 2006). My experience supports the thesis that interacting via avatars can alter the relationships between teachers and students and encourage participation from students who are often less involved in the traditional classroom. ${ }^{11}$ As Herold notes, "Anonymity did help students... express themselves more freely... Students were more willing to express their opinions, ask questions, or even to disagree with the lecturer than... when facing a teacher in a classroom" (Herold 2009: 14). The above-mentioned student, who arrived in our SL classroom ready to disco, contributed infrequently to D2L discussions. My impression is that when identified by name, he resumed a reticent and introverted demeanor. For students who are not shy to speak in class, the degree to which anonymity contributed to increased learning (or to freer posts on our D2L discussion board, which displays students' real names) remains an open question.

Another potential bonus of utilizing avatars is that avatar appearance can elicit unconscious associations in users' minds, affecting both cognition and user behavior. In a study performed in Second Life, researchers found that "avatar visual appearance and role labels had unconscious effects over participant's language use" such that seeing an unnamed avatar dressed as a professor prompted subjects to incorporate vocabulary related to education in their writing (Peña, et al. 2012: 13). When the research team named the avatar Professor So-and-So, the effect was compounded. Based on these findings, it is possible that presenting students with stereotypically Asian-looking avatars or avatars dressed in Asian-inspired 


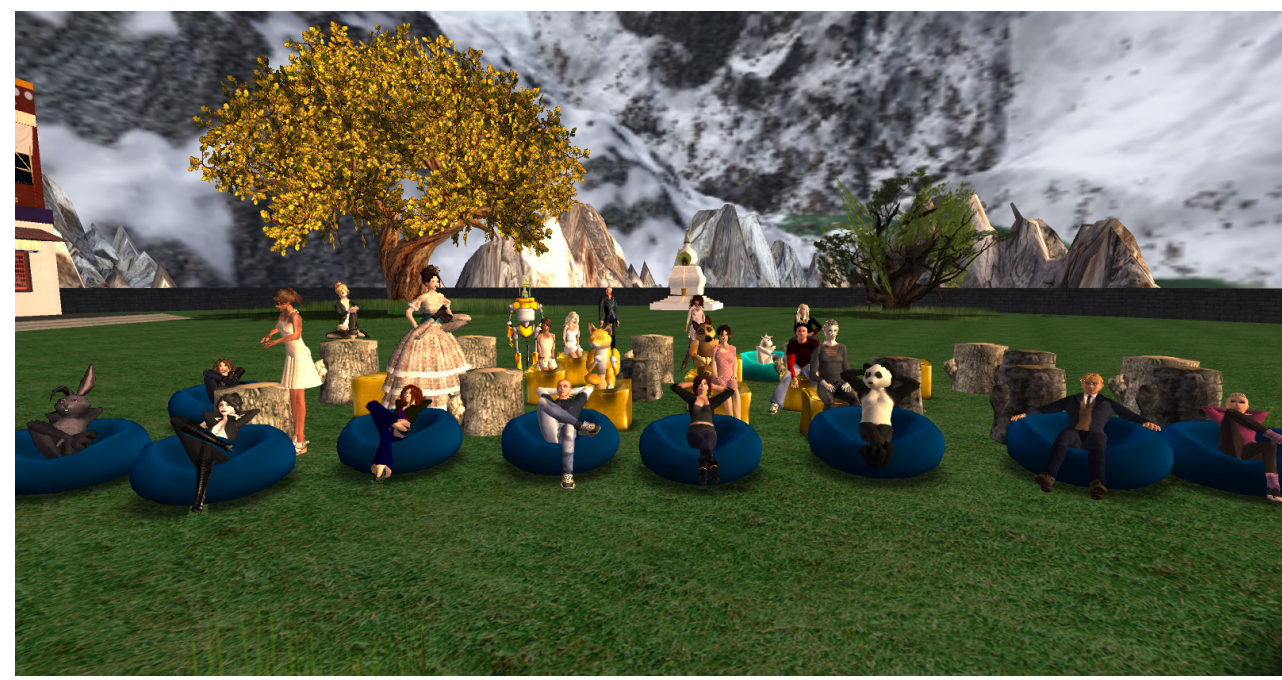

Figure 2: Student avatars arriving for class

clothing could positively influence the learning of Asian-related content by increasing students' use of Asian language vocabulary. Furthermore, if "avatar features unconsciously activate associations along a network of semantically related ideas," the SL environment could be constructed in such a way as to present students with other visual cues that would act to tap into their mental storehouse of relevant concepts (Peña, et al. 2012: 4).

\section{THE ENVIRONMENT}

Conferencing programs can add a synchronous element to online teaching, but they lack the three-dimensional environment that platforms such as SL provide. This is one of the most commonly cited advantages of virtual worlds. From providing "a robust location for culture" (Boellstorff 2008) to enhancing interactivity (Petrakou 2010), the environment of SL adds a spatial dimension which augments one's feeling of "being there." This "sense of space, locality, presence, and dynamic conditionality with other users" offers an "immersive experience" that video conferencing media lack (Kim et al. 2012: 3). In a comparison of SL and video conferencing programs, SL outranked conferencing programs in terms of sense of presence (both individual and social), interactivity, and self-presentation, and was rated equivalent to video conferencing for realism (Van der Land et al. 2011).

Our classroom for Eastern Religious Thought was located on UWW's Athena Island in a space designed as an outdoor courtyard with a willow tree, PowerPoint slide board, and various seating options. Before the course began, the area was modified to include a Tibetanstyle Buddhist temple and stūpa, lending an Asian atmosphere to the setting. ${ }^{12}$ In this regard, the visual component of the course was significantly more interesting than it would have been if students had watched my face on their computer screens. The "visual metaphor" and "visual narrative of the course content" that SL allows work to anchor students in a visual environment and can contribute to learning (Dickey 2005). When I solicited our tech assistant's feedback at the end of the term, for example, she recalled the day I demonstrated circumambulation with my avatar by having it walk in a clockwise direction around the slide board. She suggested that in the future, "We could have an animation prepared where your avatar went through all the ritual motions of that prayer." Such possibilities are obviously not available in traditional video conferencing platforms.

Animations for prostrations and ritual hand-washing also exist in other SL locations. ${ }^{13}$ Among the better for teaching Asian religions are realistic Buddhist temples where users can click a button labeled "prostrate" or "meditate" and watch as their avatars perform pros- 
trations in front of a Buddha image or sit in lotus posture on a meditation cushion. What is exciting about this for teaching Asian religions is that students do not need to know how to do a prostration; they do not need to be able to sit in lotus posture using their real legs. Programmed animations take control of avatars, making the actions automatic. With one click of the mouse, in Tibetan-inspired SL sites, one's avatar does Tibetan-style full body prostrations; in Chinese-inspired sites, one's avatar kow-tows.

The opportunity to immerse oneself in simulated 3D environments, territory that is otherwise "historically lost, too distant, too costly, imaginary, futuristic or impossible to see by the human eye," is an exciting feature of SL (Warburton 2009: 421). Within SL, East Asian-inspired locations, especially Japanese sites, are more numerous than Inner, South, or Southeast Asian locales, and Buddhist locations far outnumber those of other Asian religious traditions. ${ }^{14}$ Sites associated with SL's "Buddha Center," where users from all over the world $\log$ in for regularly scheduled meditation sessions, are particularly noteworthy. ${ }^{15}$ These include "Sukhavati," ${ }^{16}$ where avatars meet daily at Amitābha and Kwan Yin shrines for chanting, sometimes done to background music of Om shanti shanti, and "Deer Park," where I attended lectures appropriate for beginning audiences. Other well-crafted SL Buddhist environments include "Zen Retreat," ${ }^{17}$ which hosts regular zazen sittings and Tibetan language classes, "Kannonji Zen Retreat,"18 and "Drolma Lhakhang."19

SL locations related to Asian religions other than Buddhism were more difficult to find. For Hinduism, "India Gardens" hosts a temple devoted to Ganesh, plays Hindu devotional music, and enables avatars to sit in meditation or ride an elephant. ${ }^{20}$ The altar, fronted by a signboard instructing visitors to remove their shoes, hosts attention-grabbing animated mice helpful for spurring discussions about Hindu deities' vehicles (vāhana). A somewhat undeveloped but aesthetically pleasing Shintō location in SL is "Oltonfell," where avatars can wash their hands in a traditional water trough. ${ }^{21} \mathrm{I}$ did not successfully locate sites for Jainism, Daoism, Confucianism, or Sikhism. Instructors can mitigate the current lack of SL locations representing these traditions through slideshows and video clips, whether shown in the online classroom or posted to D2L or other accompanying course management system.

While SL environments are useful for giving a sense of the aesthetics of a Zen temple or Hindu shrine, they are far from authentic representations of the real world. Depending on the expertise and motivations of their creators, many Asian environment simulations range from picturesque stereotypes to bizarre fantasy worlds. Numerous Buddhist sites combine elements of Japanese, Chinese, and Tibetan music, architecture, and iconography. Others are clearly unaware of what is and is not culturally appropriate in certain contexts. The "Skeptical Buddhists Sangha," for example, identifies their teleport pads with a Buddha image superimposed on a mandala. ${ }^{22}$ The teleports are located on the ground, and avatars contact them by to stepping onto them. Similarly, when one teleports between locations, one arrives standing on the Buddha-mandala teleport pad. Some of these issues could be taken as opportunities rather than drawbacks, however, as instructors could take advantage of problematic SL environments by incorporating relevant analyses into the course, such as a discussion about why standing on an image of the Buddha is objectionable. ${ }^{23}$

\section{GUEST LECTURE}

One of the most successful applications of SL in our course was a guest lecture given by a monk at Deer Park Buddhist Center in Oregon, WI. In preparation for his appearance, the tech assistant modified the college's guest avatar to resemble a Tibetan Buddhist monk by removing the avatar's hair and dressing him in maroon robes. On the evening of his talk, 


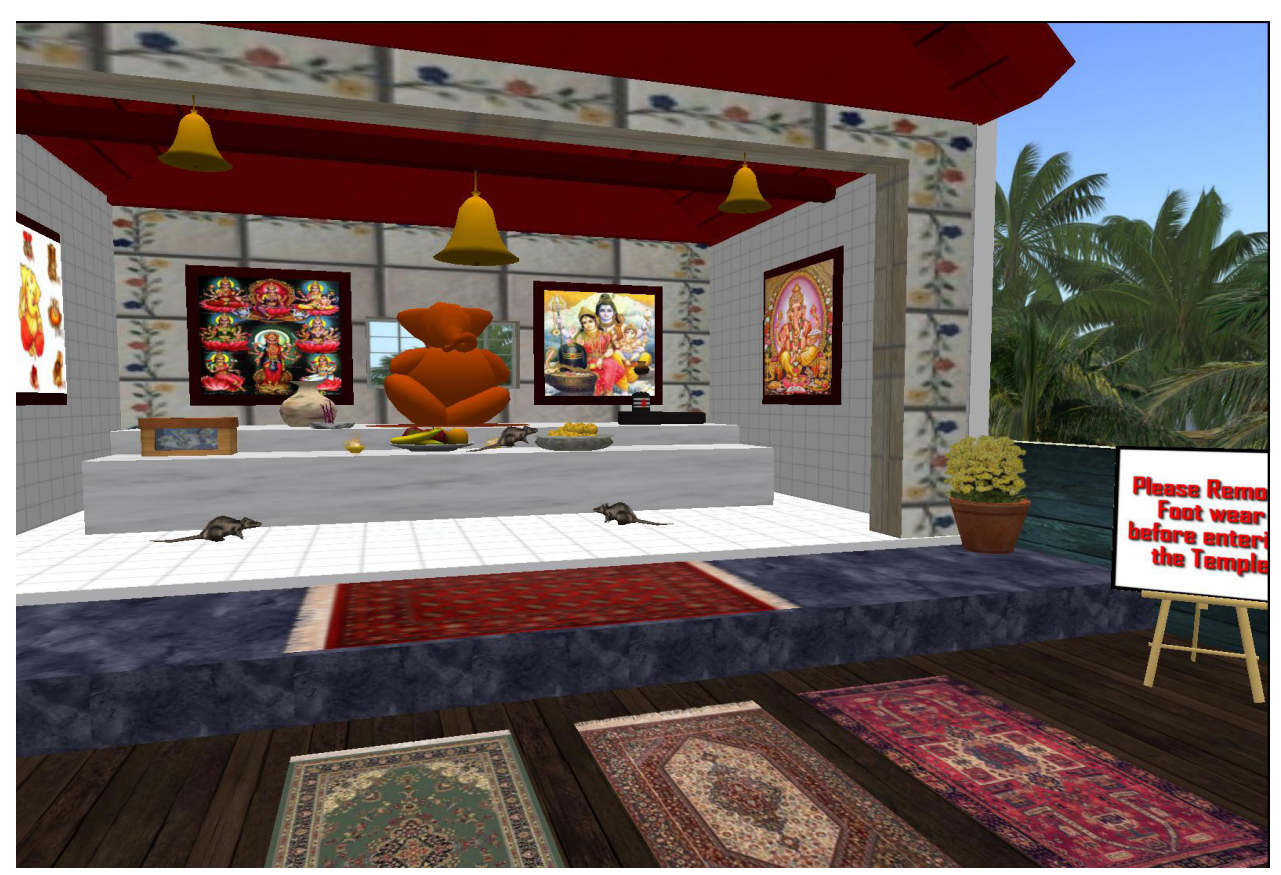

Figure 3: Ganesh Temple at "India Gardens"

the (human) monk logged in to SL from his monastery room and, appearing as his monk avatar, spoke to the student avatars about Vajrayāna Buddhism and monastic life. Students were thrilled to be able to listen to and ask questions of a monk. Many described his lecture as the most exciting element of the course. For computer-savvy individuals with fast internet connections, it is not difficult to $\log$ in as an already-established avatar. After receiving one instructional email, speaking with me on the phone, and executing a practice log in, the monk had no trouble performing basic functions in SL. For him, the time needed to learn to navigate SL was less than and preferable to an hour-long drive from his monastery to UWW's campus.

Instructors teaching in SL can also search within SL for "residents," particularly those based in Asia, to invite to their virtual classroom. Of course, finding and coordinating with SL users who are appropriately knowledgeable about the subject matter, able to communicate effectively in English, and willing to log on during class time (likely very late at night or early morning in Asia) requires extensive time and effort. As well as the risks associated with hosting unfamiliar presenters in a face-to-face classroom, instructors organizing a distance lecture in SL must be prepared for technical difficulties when the invited speaker attempts to connect in the virtual world.

\section{TECHNICAL PROBLEMS IN SECOND LIFE}

The significant drawback of using SL for online teaching lies in the technical problems students and staff, especially those new to online virtual worlds, inevitably encounter. Although proponents of 3D virtual worlds view them as logical extensions of our increasingly digital lives, many students and instructors have difficulty with SL. Even gaming experts have complained of SL's endless complications, calling it "really painful to use and hard to navigate" (Terdiman 2010). ${ }^{24}$

Before it can be used as a teaching platform, both instructors and students must dedicate a significant amount of time to learning SL's controls. Having never played computer games, I spent approximately ten hours familiarizing myself with the basics: learning to navigate and position my avatar and to adjust my camera and volume controls, as well as exploring locations outside the dedicated online classroom. Two weeks before the course began, 
students were provided with instructions for doing the same. Nevertheless, our first class meeting was devoted entirely to helping students adjust their computer and SL settings and find their way to the classroom. Since I was hardly proficient in SL myself, the tech assistant and an experienced faculty member logged in and assisted me in orienting students. Aside from the hours I spent searching for potential fieldtrip sites, by the fourth week of the term, use of SL did not require a considerable amount of extra time on my part. This is largely due, however, to the fact that the tech assistant continued to be present for all of our class meetings to assist students who had trouble hearing or seeing the slides. In addition to responding to occasional student emails about SL, she regularly spent an hour each week uploading my PowerPoint slides and troubleshooting other technical issues. ${ }^{25}$

"The high hardware requirements of the client software" compared to "the relatively cheap equipment used in most educational institutions" present a common hurdle to using SL for teaching (Herold 2012: 7). Although my university-issued computer was less than a year old, it required an updated graphics card in order to run SL successfully. On three occasions, my headset disconnected from the computer as I was lecturing, forcing me to log out and restart SL in order to continue. ${ }^{26}$ Several students found their personal computers unable to handle SL's hardware requirements, and one student had to commute an hour to campus in order to use university computers, thus negating the convenience of an online course.

Reliable and sufficiently fast internet connections were a continuing source of frustration throughout the term. Although our virtual classroom was designed to be minimally taxing on bandwidth so as not to cause unnecessary lag, students quickly discovered that the internet provided in their dorm rooms was insufficient for maintaining a connection to SL. Even the student who commuted to campus in order to use a university computer ended up logging on through the tech assistant's personal laptop when SL stopped running on the machines in the campus lab. "I had trouble all semester with the technology," one student complained on his/her course evaluation, and student feedback at the end of the semester indicated even more problems than I was aware of during the course. One comment read: "I am going to get a grade based on my attendance in SL and it took me all semester to figure out it was because of my internet connection and not the program. Half the time I was as I thought [sic] logged in and in fact my internet connection couldn't support the program requirements so I was not actually there (I think) at least no one would answer me and the slide show didn't change."

The speed of my home internet connection was not fast enough to run SL either. Since I could connect to SL only from my office computer, teaching online was no more convenient for me than teaching in a classroom. Aside from technical problems, another drawback to using SL was that I could not see when students were having trouble logging on, viewing the PowerPoint slides, or communicating with the rest of the group. ${ }^{27}$ Throughout the course, I posted my PowerPoint slides online, and towards the end of the semester our classes were video-recorded in-world and the recordings posted for students to view. Recording within SL requires additional time and expertise on the part of support staff, but it mitigated student frustration considerably.

\section{EVALUATION}

For SL to be a worthwhile use of time and resources, instructors must take advantage of the unique occasions for anonymity, fieldtrips, and props that the virtual world offers. ${ }^{28}$ Herold (2009) lists four benefits of using SL that are relevant for introductory courses centered on Asia or religion: avatar appearance allows for anonymity, there are educa- 


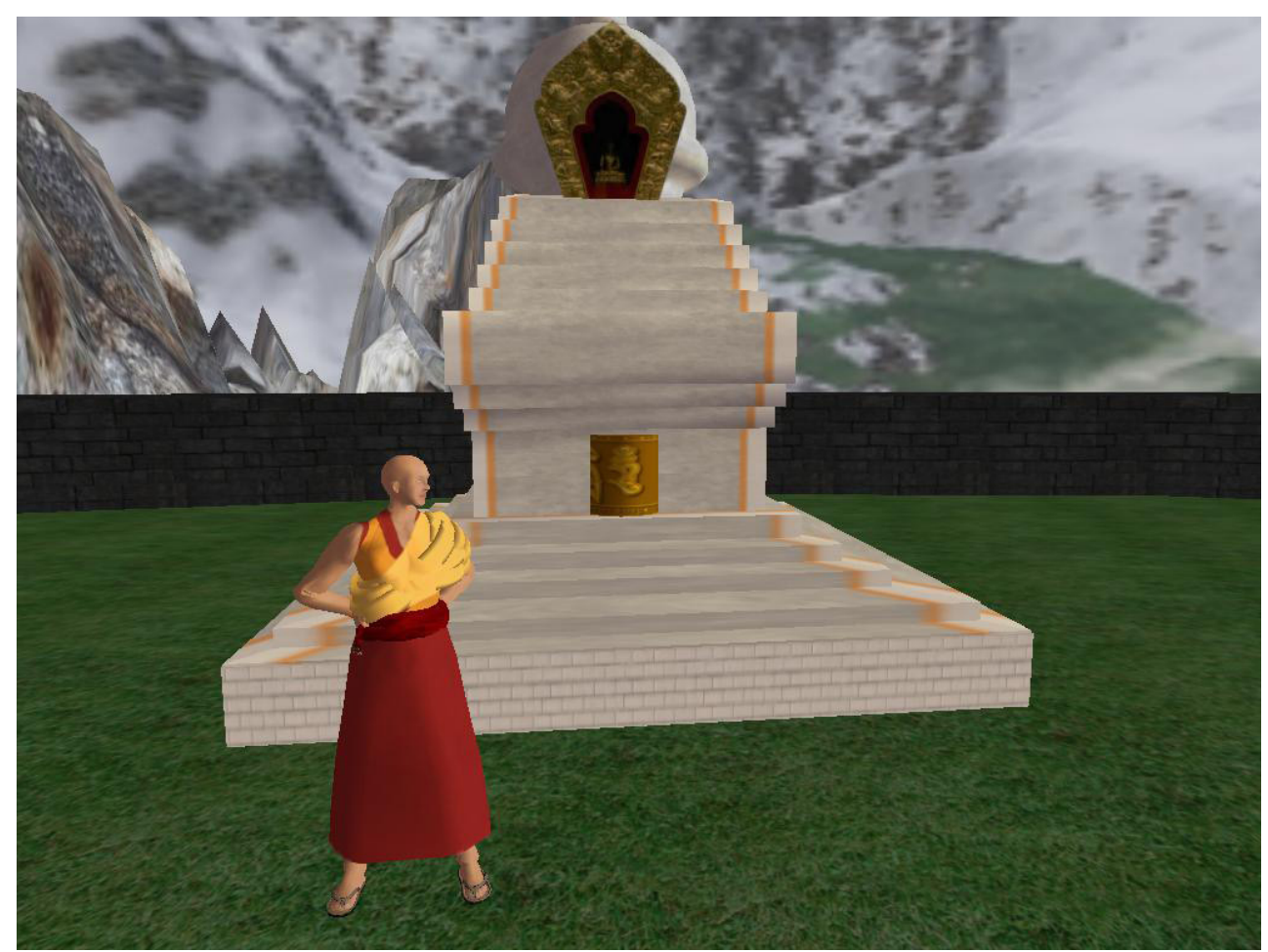

Figure 4: Avatar dressed as a Tibetan monk

tional locations in SL for students to explore, guest lecturers can participate remotely, and instructors can create multi-national courses made up of classrooms of students in different countries. With the exception of making one's avatar anonymous, taking advantage of these benefits requires additional effort on the part of the instructor. In addition, fieldtrips must be required and incorporated into the course in order for students to take advantage of that opportunity. Herold (2012) noticed in his study of over 4,000 undergraduates that most students only logged in and out for class and did not explore the larger SL environment. When I offered extra credit for exploring some of the locations mentioned above, only two students did so.

Kaye and Spurgin (2011) write that while the virtual world is "less than real," it is also "more than fake... [and] one's activities there may bear on one's real life." At the end of our course, I found that students had gained a basic familiarity with the Asian traditions we studied and had become more critically aware of their own beliefs and those of their classmates. The former was the result of assignments and lectures. As it turned out, and as is typical at UWW, many students waited until we had met in SL and I had gone over the material orally before they attempted the reading and homework assignments. Students wrote on their course evaluations that the synchronous element of the course made them feel "more accountable" and made it "easier to stay committed" than D2L-only online formats. Students' increased awareness of their own and others' views developed through use of the D2L discussion board and, one could argue, was facilitated by the sense of community gained from interactions in SL. Otherwise, although SL added an interesting 3D visual element to our classroom, because we made minimal use of the unique props and animations available, a video conferencing program might have served our needs equally well. ${ }^{29} \mathrm{In}$ fact, we would have encountered fewer technical difficulties and still been able to engage in synchronous dialogue.

At the end of the semester, how did students feel about the use of SL in our course? More than one student expressed dissatisfaction on his/her evaluation, but no student dropped the course due to difficulties with SL. Several traditional students voiced strong opposition 
to the online nature of the course prior to the start of the semester, and their experience using SL did not alter their preference for face-to-face classes. "It's great to be a blimp on Second Life and all, but I would rather be face to face with my professor. It's like I'm paying more for less," one student remarked..$^{30}$ Online students, on the other hand, were enthusiastic and recommended using SL again. "I loved that we used Second Life. I have been taking online classes all year and sometimes you forget that there are actually other people even in your class. It was neat to hear voices, say jokes, ask questions and have them answered immediately. It created a real sense of a classroom which I found so refreshing," one student commented. Even traditional students appreciated the sense of community that SL provided: "I think that SL was a great way to make the online class feel more hands on. I think it would be a great tool to incorporate into all online classes. Overall this was a great class, and probably my favorite of the semester despite being online (generally I do not like online classes, SL really helped to improve [the] online [nature of the] class)." "I would have liked to have had this course in a classroom, but Second Life really made it feel more class-like," another wrote. These comments support Warburton's claim that embodiment as an avatar, combined with the multiple modes of communication that SL allows, can impact "the affective, empathic and motivational aspects" of the online course experience (Warburton 2009: 421). Other impressions of SL included "very fun" and "successful," observations that reflect my own experience as an instructor.

Online students unanimously preferred SL to non-synchronous options, and I am convinced that the synchronicity SL provided worked to create a sense of community normally lacking in web-based classes. If asked to offer an online course again in the future, I would give SL another try. Now that I have developed a degree of proficiency navigating the virtual world, I would look forward to utilizing more of what it has to offer. In the meantime, I would hope to see university resources upgraded to better support SL. Given a choice between teaching this course online or in a traditional face-to-face classroom next spring, however, I chose the traditional classroom.

Special thanks to Chris Calvert-Minor and Jessica Hazlett.

\section{NOTES}

1. See Kim et al. 2012: 2. Herold's (2012) report of his experience using SL at Hong Kong Polytechnic University is a helpful study, as is Calvert-Minor 2011.

2. Kim et al. (2012) found sixteen reports describing the use of SL in foreign language courses, eight in computer education, eleven in general education, twelve in the sciences, five in interdisciplinary education, three in economics, two in design, and eight in other disciplines.

3. When I checked at 9:45pm CST on May 27, 2012, there were over 50,000 users online. According to one resident's blog, the average number of avatars online together over the past twelve months usually tops 40,000 http://dwellonit.taterunino.net/sl-statistical-charts accessed 8/2/2012). Other sources give figures as high as 60,000 .

4. UWW has currently developed a planetarium, a partial recreation of the Auschwitz II-Birkenau concentration camp, a crime scene for practicing forensic procedures, and a lab-safety training simulation.

5. Although there exist various multi-user virtual environments, SL is by far the most widely used, both in the U.S. and abroad. Warburton (2009) cites a study published in 2008 which estimates that three-quarters of British universities are using or actively developing a presence in SL.

6. D2L provided a needed forum for students to express their considered ideas, an observation echoed by Petrakou 2010.

7. SL's generic avatars, especially female avatars, are highly sexualized. It is difficult to find conservative clothing, and ready-made female body shapes must be altered in order to appear normal. Some studies have found that sexualized avatars contribute to the sexualization of (human) women and that seeing oneself represented as a highly-sexualized avatar influences user behavior both on and offline. See Fox et al. 2013.

8. Calvert-Minor (2011) found that students reported increased participation in the SL classroom as compared to a traditional classroom.

9. Now, a year later, this student continues to visit me and inform me of news related to the pop star and to events, both contemporary and historical, concerning blimps. It seems the imaginative nature of the SL experience served to bring him out of his shell. 
10. See, for example, Meadows 2008.

11. See also Dickey 2005 and Kim et al. 2012.

12. Based on the findings of Peña et al. 2012, in a future course I would request additional artifacts, including a Shintō torii and Hindu lingam, and have each artifact labeled with its corresponding term.

13. Grieve argues that SL delivers "an immersed bodily performance... in cyberspace" (2010, p. 37). Achieving a sense of immersion in the virtual environment, however, requires more advanced user skills than college and university students and instructors are likely to possess. The quality of the user-created locations varies considerably from those that are worthwhile for class fieldtrips to those that are embarrassingly inappropriate for young users. Before sending students out to explore, it is incumbent on the instructor to investigate locations ahead of time. Warden et al. 2013 note the presence of "unpredictable offensive material" due to SL's primary function as a venue for online entertainment.

14. "Kurugawa Machi" (Kurugawa Machi 11: 112, 84, 50) represents Edo-period Japan and was created for educational as well as role-playing purposes: "As a roleplaying group we strive for authenticity as much as possible. In that spirit you will be required to wear Edo Period Japanese costume and hairstyles" (http://www.blueheronenterprises.com/greetings/ookuma_en accessed 5/31/2012). Herold (2010) used "RMB City" in his classroom (RMB City: 128, 128, 4 and 143, 32, 126). While it describes itself as "an online art community" and "a reflection of China's urban and cultural explosion," the day I visited "RMB City," I encountered posters of nearly-nude female avatars advertising an upcoming dance party (http://rmbcity.com accessed 8/3/2012). Perhaps a more useful site for China and Chinese language is Monash University's "Chinese Island" (Chinese Island, Monash University 2: 203, 143, 26). Note: Finding locations within SL can be confusing when one is confronted with names of regions, parcels, and sub-locations. The addresses I provide here are not the only coordinates within the sites.

15. Buddha Center: 145, 135, 21. According to its creators, "The basic tenet is that Buddhism must be unequivocally and purely taught by experienced monastics and lay people of Second Life" (http://www.thebuddhacenter.org/about accessed 5/31/2012). For a history of the Buddha Center in SL, see Connelly 2010.

16. Pure Land Buddhist Practice, Sukhavati: 224, 197, 25.

17. Zen Retreat, Rieul: 201, 221, 73.

18. Zen Retreat (Snowlion Mountain, Kagyu Phuntzok Gatsel Choling: 172, 149, 22) is affiliated with the Sweeping Zen website. Its creators' aim is to provide "a small place for tech-savvy individuals to gather together and meditate" (http://kannonjiretreat.com accessed 6/2/2012). Its website poses the provocative question: "If... meditation is above all else a body practice, how then can having a pixelated version of ourselves sitting down on a meditation cushion that exists only on a computer monitor be of any real benefit to people?" The reply: "The short answer is community. We invite people from all over the world to come take a moment out of their day to sit with others, all in an atmosphere that helps symbolize what we're all doing at that moment in our homes" (http://kannonjiretreat.com accessed 6/2/2012). For discussion of Buddhist meditation in SL, see Grieve 2013.

19. Drolma Lhakhang: 40, 70, 146.

20. India Gardens, Shree Ganesha Hindu Temple: 247, 136, 27.

21. Oltonfell: $158,214,53$.

22. Skeptical Buddhists Sangha: 97, 76, 41.

23. Grieve (2010) suggests drawing from students' experiences appearing as avatars to illustrate the constructed nature of personal identity and the Buddhist concept of no-self (anätman).

24. See also Herold 2009.

25. Prior to the start of the course, the tech assistant spent an estimated fifteen hours designing the classroom's temple and improving my avatar's appearance and animations. Numerous instructors have referred to the extensive institutional support necessary for utilizing SL (Herold 2009).

26. Herold (2012) reports that several instructors at his university abandoned SL because the complexity of the environment and educational activities they designed caused such severe lagging on student computers that students were reluctant to participate.

27. Petrakou (2010) discusses this problem at length.

28. When I sat in on a colleague's summer course in SL, I found it difficult to remain focused on my computer. His slides consisted of black text on a white background, and his avatar rarely moved from its position in front of the class. In this case, the virtual world was not being used creatively to inspire or contribute to student learning.

29. Calvert-Minor describes imaginative props and animations he incorporated into his philosophy class.

30. Students paid an additional fee of $\$ 150$ to take the course because it was online.

\section{SELECTED BIBLIOGRAPHY}

Boellstorff, Tom. Coming of Age in Second Life: An Anthropologist Explores the Virtually Human. (Princeton: Princeton University Press, 2008).

Burgess, Melissa, John Slate, Ana Rojas-LeBouef, Kimberly LaPrairie. "Teaching and learning in Second Life: Using the Community of Inquiry (CoI) model to support online instruction with graduate students in instructional technology." The Internet and Higher Education 13, no. 1-2 (2010): 84-88.

Calvert-Minor, Chris. "Teaching Philosophy in Second Life: Where the Virtual World and Philosophy Instruction Meet." Teaching Philosophy 34, no.1 (2011): 1-16. 
Connelly, Louise. "Virtual Buddhism: An Analysis of Aesthetics in Relation to Reli-

gious Practice." Online: Heidelberg Journal of Religions on the Internet 4, no.1 (2010): 12-34.

http://archiv.ub.uni-heidelberg.de/volltextserver/volltexte/2010/11295/pdf/02.pdf (accessed 6/2/12).

De Lucia, Andrea, Rita Francese, Ignazio Passero, and Genoveffa Tortora. "Development and Evaluation of a

Virtual Campus on Second Life: The case of SecondDMI." Computers \& Education 52, no. 1 (2009): 220-233.

Dickey, Michele. "Three-Dimensional Virtual Worlds and Distance Learning: Two case studies of Active Worlds

as a medium for distance education." British Journal of Educational Technology 36, no.3 (2005): 439-51.

Edmundson, Mark. “The Trouble with Online Education.” The New York Times. July 19, 2012.

http://www.nytimes.com/2012/07/20/opinion/the-trouble-with-online-education.html?_r=3\&smid=fb-share (accessed 7/31/12)

Fox, Jesse, Jeremy Bailenson, and Liz Tricase. "The Embodiment of Sexualized Virtual Selves: The Proteus effect and experiences of self-objectification via avatars." Computers in Human Behavior 29, no. 3 (2013): 930-938.

Geraci, Robert. "Video Games and the Transhuman Inclination." Zygon: Journal of Religion and Science 47, no. 4 (2012): 735-756

Grieve, Gregory. Digital Zen: Buddhism, Virtual worlds and online Meditation. London: Routledge, 2013.

Grieve, Gregory. "Virtually Embodying the Field: Silent Online Buddhist Meditation, Immersion, and the

Cardean Ethnographic Method." Online: Heidelberg Journal of Religions on the Internet 4, no.1 (2010): 35-62.

http://www.ub.uni-heidelberg.de/archiv/11296 (accessed 8/2/2012).

Herold, David. "Second Life and Academia - Reframing the Debate between Supporters and Critics." Journal of

Virtual Worlds Research 5, no.1 (2012). http://journals.tdl.org/jvwr/article/view/6156/5976 (accessed 5/28/12)

Herold, David. "Mediating Media Studies - Stimulating critical awareness in a virtual environment." Computers \&

Education 54, no.3 (2010): 791-798.

Herold, David. "Virtual Education: Teaching Media Studies in Second Life." Journal of Virtual Worlds Research 2, no.1 (2009). https://journals.tdl.org/jvwr/article/view/380/454 (accessed 6/2/12).

Hornik, Steven, and Steven Thornburg. "Really Engaging Accounting: Second Life ${ }^{\mathrm{nt}}$ as a Learning Platform." Issues in Accounting Education 25, no.3 (2010): 361-78.

Jarmon, Leslie, Tomoko Traphagan, Michael Mayrath, and Avani Trivedi. "Virtual World Teaching, Experiential Learning, and Assessment: An interdisciplinary communication course in Second Life." Computers \& Education 53, no. 1 (2009): 169-182.

Kaye, Sharon, and Earl Spurgin. "Using the Internet Platform Second Life to Teach Social Justice." Teaching Philosophy 34, no.1 (2011): 29-30.

Kim, Sahoon, Jiyeon Lee, and Michael Thomas. "Between Purpose and Method: A Review of

Educational Research on 3D Virtual Worlds." Journal of Virtual Worlds Research 5, no.1 (2012).

http://journals.tdl.org/jvwr/article/view/2151/5973 (accessed 5/28/12)

Livingston, Daniel. "Second Life is Dead, Long Live Second Life?" Educause Review 46, no. 2 (2011): 62-63.

http://www.educause.edu/ero/article/second-life-dead-long-live-second-life (accessed 2/24/13)

Masmuzidin, Masyarah Zulhaida, Jianmin Jiang, and Taoran Wan. "A Pilot Study: The evaluation of Malaysian virtual folktales in Second Life." Procedia - Social and Behavioral Sciences 15 (2011): 1993-1997.

Meadows, Mark Stephen. I, Avatar: The Culture and Consequences of Having a Second Life. Berkeley: New Riders, 2008.

Ramaswami, Rama. "Is There a Second Life for Virtual Worlds?" Campus Technology (2011)

http://campustechnology.com/Articles/2011/09/01/Is-There-a-Second-Life-for-Virtual-Worlds.aspx (accessed 2/24/13)

Peña, Jorge, Matthew McGlone, and Joe Sanchez. “The Cowl Makes the Monk: How Avatar Appearance and Role Labels Affect Cognition in Virtual Worlds." Journal of Virtual Worlds Research 5, no. 3 (2012).

http://journals.tdl.org/jvwr/index.php/jvwr/article/view/6280/6302 (accessed 2/17/2013).

Petrakou, Alexandra. "Interacting through Avatars: Virtual worlds as a context for online education." Computers and Education 54 (2010): 1020-1027.

Steinkuehler, Constance, and Dmitri Williams. "Where everybody knows your (screen) name: On-

line Games as 'Third Places"' Journal of Computer-Mediated Communication 11, no.4 (2006), article 1.

http://jcmc.indiana.edu/vol11/issue4/steinkuehler.htm (accessed 6/2/12)

Terdiman, Daniel. "Where virtual worlds once ruled, FarmVille dominates." CNET News, February 26, 2010.

http://news.cnet.com/8301-13772_3-10460293-52.htm (accessed 8/6/2012).

Vallance, Michael, and Stewart Martin. "Assessment and Learning in the Virtual World:

Tasks, Taxonomies and Teaching For Real." Journal of Virtual Worlds Research 5, no. 2 (2012).

http://journals.tdl.org/jvwr/index.php/jvwr/article/view/6283/6037 (accessed 2/28/13)

Van der Land, Sarah, Alexander Schouten, Bart van den Hooff, and Frans Feldberg. "Modelling the Metaverse: A Theoretical Model of Effective Team Collaboration in 3D Virtual Environments," Journal of Virtual Worlds Research 4, no. 3 (2011). https://journals.tdl.org/jvwr/article/view/6126/5787 (accessed 6/2/12)

Warburton, Steven. "Second Life in Higher Education: Assessing the potential for and the barriers to deploying virtual worlds in learning and technology." British Journal of Educational Technology 40, no. 3 (2009): 414-426.

Warden, Clyde, James Stanworth, Jian Biao Ren, and Antony Warden. "Synchronous Learning Best Practices: An action research study." Computers \& Education 63 (2013): 197-207. 